\title{
Social support and infant malnutrition: a case-control study in an urban area of Southeastern Brazil
}

\author{
Maria Antonieta de B. L. Carvalhaes ${ }^{1,2 *}$, Maria Helena D’Aquino Benício ${ }^{3}$ and Aluísio J. D. Barros ${ }^{4}$ \\ ${ }^{1}$ Faculdade de Medicina, Distrito de Rubião Júnior, Botucatu, São Paulo, Brazil \\ ${ }^{2}$ Departamento de Enfermagem, Faculdade de Medicina de Botucatu, UNESP, Brazil \\ ${ }^{3}$ Departamento de Nutrição, Faculdade de Saúde Pública, USP, Brazil \\ ${ }^{4}$ Departamento de Medicina Social, Universidade Federal de Pelotas, Brazil
}

(Received 29 March 2004 - Revised 25 February 2005 - Accepted 19 April 2005)

\begin{abstract}
The relationship between malnutrition and social support was first suggested in the mid-1990s. Despite its plausibility, no empirical studies aimed at obtaining evidence of this association could be located. The goal of the present study was to investigate such evidence. A case-control study was carried out including 101 malnourished children (weight-for-age National Center for Health Statistics/WHO 5th percentile) aged 12-23 months, who were compared with 200 well-nourished children with regard to exposure to a series of factors related to their social support system. Univariate and multiple logistic regressions were carried out, odds ratios being adjusted for per capita family income, mother's schooling, and number of children. The presence of an interaction between income and social support variables was also tested. Absence of a partner living with the mother increased risk of malnutrition (odds ratio 2.4 (95\% CI 1.19, 4.89)), even after adjustment for per capita family income, mother's schooling, and number of children. The lack of economic support during adverse situations accounted for a very high risk of malnutrition (odds ratio 10.1 (95\% CI 3.48, 29.13)) among low-income children, but had no effect on children of higher-income families. Results indicate that receiving economic support is an efficient risk modulator for malnutrition among low-income children. In addition, it was shown that the absence of a partner living with the mother is an important risk factor for malnutrition, with an effect independent from per capita family income, mother's schooling, and number of children.
\end{abstract}

Infant malnutrition: Social support: Case-control studies

A simple definition for social support is the access to individuals, groups and institutions capable of providing help in difficult situations (Norbeck et al. 1983). In the last few years, evidence has been gathered as to the importance of social support - directly or by acting as a cushion during stressful situations - in determining individual health and wellbeing (Castro et al. 1997). It has recently been demonstrated that the lack of emotional and instrumental support increases the likelihood of delivering infants who are small for gestational age (Dejin-Karlsson et al. 2000).

Despite the references encountered in the 1960s literature to a certain amount of social isolation being part of the adverse conditions associated with malnutrition in the developing world (Morley et al. 1968; Kerr et al. 1978; Dixon et al. 1982), the notion of social support as a risk or protective factor is fairly recent. In the mid-1990s, Engle \& Ricciuti (1995) included social support network characteristics as one of the explanatory variables in a conceptual model for determining infant nutritional status. For these authors, an adequate support system might have a positive effect on nutritional care, healthcare and psychosocial practices, thus influencing child nutrition. Emotional support availability might help mothers to make adequate choices between care practices, during illness as well as normal situations. Instrumental support would make it easier for the mother to perform daily tasks, such as laundry, cooking, shopping, and taking children to healthcare facilities, resulting in more time for the mother to care for her children. Substitute care availability would expedite the setting up of alternative childcare schedules, allowing mothers to work. Economic support would reduce the impact of unemployment, or of the lack of resources for the child's basic necessities and catastrophic expenditures with healthcare. In addition, all these types of support would help reduce both maternal and child stress, having a positive effect on childcare adequacy, and especially on nutritional interaction. An adequate social support system could also play an important role in social regulation, reminding and reaffirming maternal responsibilities (Mulroy, 1997; Algel \& Wobey, 1998; Tarkka et al. 1999).

Despite the construction of a quite plausible hypothesis, up to this date no empirical study was found in the literature about social support and malnutrition. The present study is aimed at identifying the role played by a number of indicators of social support in the determination of nutritional status in urban areas with low prevalences of infant malnutrition.

\section{Methods}

The study was developed in Botucatu, a medium-sized municipality in Southeastern Brazil, with a population of approximately 103000 people, of whom $94 \%$ live in the urban area. According to the data generated by a prior anthropometric survey conducted 
during three national multivaccination days, $8.2 \%$ of children aged 12-23 months showed weight-for-age below National Center for Health Statistics (NCHS) 5th percentile in 1996/97 (World Health Organization, 1995). This is, therefore, a municipality with a low prevalence of malnutrition and a predominance of mild anthropometrical deficits, but in which there are 'pockets' of poverty typical of highly uneven societies, as is the case in Brazil. A much higher prevalence of malnutrition is expected within these pockets. (The prevalence of under-five malnutrition in this municipality in 1997 was estimated at 5.0\%; Benício \& Monteiro, 1997.)

Subjects were children aged 12-23 months of age, a period in which nutritional conditions are important determinants of health and infant survival. The highest prevalences of protein-energy malnutrition are also verified during this period. A case-control study was set up with 101 malnourished children (weight-forage below NCHS/WHO 5th percentile) (World Health Organization, 1995) compared with 200 well-nourished children (weight-for-age above 25th percentile), in terms of exposure to a number of factors indicative of the availability and functionality of the support network to which mothers had access since the child's birth. This sample size allowed for $80 \%$ power in detecting, with $5 \%$ significance, associations with odds ratios $\geq 2.5$ for factors with exposure among controls ranging from 20 to $60 \%$ (Cousens et al. 1995).

Case and control recruitment was carried out in two stages. In the first stage, children aged 12-23 months present at one of three national immunisation campaigns (1996-1997) were weighed. Such campaigns have over $90 \%$ population coverage.

During pre-selection, children within the age group of interest who came to each vaccination facility were identified, numbered, and weighed, weight-for-age data being obtained for 1288 children. This procedure yielded 112 potential cases (of which 108 were located at their homes, and 101 were confirmed after a second weighing) and 876 potential controls. We selected as potential controls the two children vaccinated immediately following each potential case that fulfilled the anthropometric criteria defined. Of the 224 controls selected, 210 were weighed again at their homes and 200 were confirmed as controls. There was no pairing between the groups with regard to socio-economic criteria or any other criteria, confounding being controlled through adjusted analysis.

\section{Variables studied}

Measuring social support for use as an explanatory variable in epidemiological studies poses a number of difficulties, since it is a multidimensional phenomenon of behavioural nature. According to Barrera (1986), the definition and employment of the 'social support' concept should contemplate three dimensions: (a) degree of social interaction, which may be measured by exploring social network size and the intensity and nature of the relationship between individuals and other individuals and institutions; (b) perceived social support, that is, to what extent an individual believes he will receive support in case of need, and for what types of problems; (c) received social support, that is, characteristics of aid obtained (emotional, informational, material, and evaluative support) in different circumstances in which it was needed.

The information collected in the present study was intended to encompass the three dimensions of the 'social support' concept presented earlier. Initially, the presence of a partner living with the mother, and the type of financial support provided by the child's father, if absent, were investigated. Next, the number of individuals and institutions with which the mother kept contact and the type of connection and frequency of individual contact between the mother and these individuals and institutions were recorded (support availability).

Mothers were also interrogated about how sure they were of receiving help from these individuals and institutions in face of the daily life problems presented (presumed support).

Social support network efficiency (received support) was studied by questioning mothers about the type of aid received in a number of different scenarios: housekeeping or childcare immediately after birth; complete lack of money and urgent need for it; no water, electricity, or cooking gas due to lack of payment; no food for the child; no prescription medication for the child. All such events have a potential negative impact on childcare. After univariate analyses, a score for received support was constructed, combining variables related to received support adequacy that were associated with nutritional status in analyses adjusted for family income and maternal schooling. In order to test the hypothesis of interaction between support and per capita family income, new variables were created combining these two variables. Variables employed for measuring social support system adequacy are presented in Table 1.

Data were obtained through household interviews conducted by two interviewers with previous experience in epidemiological surveys. Data collection was supervised by one of the authors, and included her presence at $20 \%$ of interviews and the verification of a random $5 \%$ sample of the remainder. In order to minimise child classification errors concerning the factors investigated, both interviewers and mothers were kept unaware of the child's status as case or control. In addition, interviewers were not informed about the hypotheses under investigation.

This research project has been approved by the Research Ethics Committee of the Faculdade de Medicina de Botucatu/UNESP. The mothers, following a thorough explanation of the project's objectives and procedures, signed a consent form.

\section{Analytical procedures}

In order to identify potential confounders in the association between social support and malnutrition, we analysed the distribution of cases and controls with regard to maternal and socio-economic variables. Next, a logistic regression analysis was carried out between each variable and the child's nutritional status, and crude odds ratios were calculated. Multiple analysis was then performed for variables related to social support that were associated with nutritional status $(P<0 \cdot 10)$, crude odds ratios being adjusted for per capita family income, mother's schooling, and number of children.

The presence of an interaction between income and the social support variable was tested by logistic regression, using a variable that combined this information in defined strata: presence or absence of adequate support for low-income and higher-income households. The hypothesis being tested was that the lack of support would have greater importance for children at greater risk of malnutrition due to low income. The presence of an interaction between income and the absence of a partner was also tested using the same procedure.

Analyses were carried out using SPSS 6.0 software (SPSS Inc., Chicago, IL, USA), according to the procedures recommended by Hosmer \& Lemeshow (1989), adopting $P<0.05$ as the critical 
Table 1. Variables employed for measuring social support system adequacy

\begin{tabular}{|c|c|}
\hline Variable number & Description \\
\hline 1 & $\begin{array}{l}\text { Presence of partner living with the mother, yes or no. } \\
\text { If yes, is he the child's father? }\end{array}$ \\
\hline 2 & $\begin{array}{l}\text { Available support: presence or not of relatives, friends, } \\
\text { or neighbours with which the mother believes she can } \\
\text { count on in case of difficulty, and with which she } \\
\text { maintains personal contact at least once per month }\end{array}$ \\
\hline 3 & $\begin{array}{l}\text { Participation or not in church, union, neighbourhood } \\
\text { association, service clubs, support groups, and } \\
\text { non-governmental organisations, and belief that } \\
\text { she can count on these institutions in case of need }\end{array}$ \\
\hline 4 & $\begin{array}{l}\text { Presumed support for money loans: the mother } \\
\text { informed if she had anyone from whom she could } \\
\text { obtain money in case of urgent necessity }\end{array}$ \\
\hline 5 & $\begin{array}{l}\text { Presumed support for emotional problems: the } \\
\text { mother informed if she had anyone on whom } \\
\text { she could count during an emotional crisis or } \\
\text { in case she needed a person with whom to talk }\end{array}$ \\
\hline 6 & $\begin{array}{l}\text { Post-labour support: the mother informed if she } \\
\text { received assistance in caring for her } \\
\text { newborn (yes/no) }\end{array}$ \\
\hline 7 & $\begin{array}{l}\text { Support received from the child's father during the } \\
\text { previous month, in case he did not live with } \\
\text { the mother (yes/no) }\end{array}$ \\
\hline 8 & $\begin{array}{l}\text { Support received during latest crisis: the mother was } \\
\text { asked to identify, in the first place, if she had been } \\
\text { through this problem, and, if yes, the type of help } \\
\text { provided. Support adequacy categories } \\
\text { were created }\end{array}$ \\
\hline 9 & $\begin{array}{l}\text { Support received if out of cooking gas: this and the } \\
\text { following four variables }(10,11,12 \text {, and } 13) \\
\text { were investigated in the same way as variable } 8\end{array}$ \\
\hline 10 & $\begin{array}{l}\text { Support received in case of water or electricity cuts } \\
\text { due to lack of payment (latest episode) }\end{array}$ \\
\hline 11 & $\begin{array}{l}\text { Support received in case of lack of prescription } \\
\text { medication for child when the latter was sick } \\
\text { (latest episode) }\end{array}$ \\
\hline 12 & $\begin{array}{l}\text { Support received in case of lack of food for the child } \\
\text { (latest episode) }\end{array}$ \\
\hline 13 & $\begin{array}{l}\text { Received support score: variable constructed from } \\
\text { the combination of variables } 9 \text { and } 10\end{array}$ \\
\hline 14 & $\begin{array}{l}\text { Per capita family income, categorised as } 4 \text { th }+3 r d+2 n d \\
\quad \text { quartiles or } 1 \text { st quartile }\end{array}$ \\
\hline 15 & $\begin{array}{l}\text { Mother's schooling, categorised as }<4 \text { years or } 4 \text { or } \\
\text { more years }\end{array}$ \\
\hline 16 & Number of children, categorised as ' $1-2$ ' and ' $3+$ ' \\
\hline 17 & $\begin{array}{l}\text { Presence of partner according to per capita family } \\
\text { income, categorised as: with partner and adequate } \\
\text { support, or without problems (baseline); with partner } \\
\text { and without support; without partner and with support; } \\
\text { without either partner or support }\end{array}$ \\
\hline 18 & $\begin{array}{l}\text { Received support score and per capita family income } \\
\text { combined: high income with support, or without } \\
\text { problems (baseline); low income with support; high } \\
\text { income without support; low income without support }\end{array}$ \\
\hline
\end{tabular}

level for considering a factor under investigation as being associated with malnutrition.

\section{Results}

Table 2 presents the differences between cases and controls in terms of family per capita income, schooling, and number of children, indicating a less favourable scenario among controls.

Table 3 presents the main characteristics of the support systems available to studied mothers. About one-quarter of mothers of case children and $11 \%$ of mothers of control children lived with- out a partner. Roughly half of mothers from both groups maintained a close and frequent relationship with relatives, friends, and neighbours, and considered them as potentially capable of providing help under certain circumstances. Socially isolated mothers were a small fraction of both groups. However, they were more frequent among cases; $8 \%$ compared with $4.0 \%$ among controls.

Attending or maintaining some sort of connection with neighbourhood associations, community groups, or other entities potentially capable of providing support was also quite rare. The only institution with which a significant amount of mothers maintained some sort of connection was the Church. Nevertheless, mothers had similar opinions as to the possibility of counting on any help from this institution in case of need; approximately $70 \%$ of mothers considered this hypothesis as unlikely (data not shown).

When hypothetical scenarios were presented, for which mothers were to indicate whether they believed in the possibility of receiving help, a few differences and several similarities were observed between both groups: $16.8 \%$ of case mothers and $8 \%$ of control mothers declared that they did not have anyone from whom to obtain money loans in case of need (crude odds ratio $2.3 ; P=0.02$ ); approximately $29 \%$ of case mothers and $21.0 \%$ of control mothers had no one to resort to in case of emotional problems (crude odds ratio $1 \cdot 6 ; P=0 \cdot 1$ ); roughly $90 \%$ of mothers from both groups declared having access to advice in case of difficulties related to education and childcare, health services being pointed out as the institutions most likely to provide this type of support.

The actual help received - in case of real-life difficulties - was unfavourable towards malnourished children in several situations; not having received help when out of cooking gas and during electricity or water cuts due to lack of payment accounted for a rise in malnutrition risk (crude odds ratios ranging from 3.3 to 4.6). Despite its significant association with malnutrition, the variable 'support received when out of food' was excluded from analyses due to the low frequency of the category 'child remained foodless'. Groups did not differ in relation to other scenarios, such as lack of prescription medication for the child.

Table 4 shows the effects of absence of a partner, lack of presumed support for money loans, and received support score, adjusted for per capita family income, mother's schooling, and number of children.

Children whose mothers lived without a partner were roughly twice as likely to be malnourished, regardless of per capita family income, schooling, and number of children. The variable related to presumed support lost its association with nutritional status after adjustment for income.

Concerning actual financial support, expressed by variable support score, we observed, in crude analysis, that the lack of support in face of adverse situations was associated with a greater risk of malnutrition. Adjusted analyses led to alterations in the magnitude of odds and loss of statistical significance. However, we detected an important interaction between income and received support score, which is shown in Table 5.

When compared with mothers who had not been through gas, water and energy cuts due to lack of payment, those who received financial support in order to rapidly solve such problems were not at greater risk of having malnourished children. Both categories of the 'received support score' variable were then grouped in order to constitute the baseline risk category. 
Table 2. Distribution of cases and controls according to socio-economic and demographic variables (Botucatu, Brazil, 1997) (Odds ratios and $95 \%$ confidence intervals)

\begin{tabular}{|c|c|c|c|c|c|c|}
\hline \multirow[b]{2}{*}{ Variable } & \multicolumn{2}{|c|}{ Cases } & \multicolumn{2}{|c|}{ Controls } & \multirow[b]{2}{*}{ Odds ratio } & \multirow[b]{2}{*}{$95 \% \mathrm{Cl}$} \\
\hline & $n$ & $\%$ & $n$ & $\%$ & & \\
\hline $8+$ & 26 & $26 \cdot 0$ & 70 & $35 \cdot 0$ & $1 \cdot 0$ & - \\
\hline $4-7$ & 45 & $45 \cdot 0$ & 99 & 49.5 & $1 \cdot 2$ & $0.69,2 \cdot 17$ \\
\hline$\leq 3$ & 29 & $29 \cdot 0$ & 31 & $15 \cdot 5$ & 2.5 & $1.28,4.96$ \\
\hline$P$ & & & & & 0.02 & \\
\hline 4th $(\geq \mathrm{R} \$ 179 \cdot 00)$ & 16 & $16 \cdot 7$ & 58 & $29 . .9$ & $1 \cdot 0$ & $0.47,2 \cdot 19$ \\
\hline $3 \mathrm{rd}(\mathrm{R} \$ 107-178.00)$ & 19 & $19 \cdot 8$ & 53 & $27 \cdot 3$ & $1 \cdot 0$ & $0.47,2.19$ \\
\hline 2nd $(\mathrm{R} \$ 68-106 \cdot 00)$ & 19 & $19 \cdot 8$ & 53 & $27 \cdot 3$ & 1.4 & $0.68,2.97$ \\
\hline 1st $(\mathrm{R} \$ 67.00)$ & 42 & $43 \cdot 8$ & 30 & $15 \cdot 5$ & $4 \cdot 2$ & $2 \cdot 07,8.61$ \\
\hline$P$ & & & & & 0.001 & \\
\hline \multicolumn{7}{|l|}{ Number of children§ } \\
\hline 1 & 33 & $32 \cdot 7$ & 83 & 41.5 & 1.0 & - \\
\hline 2 & 25 & 24.5 & 63 & 31.5 & $1 \cdot 0$ & $0.54,1.85$ \\
\hline$P$ & & & & & 0.06 & \\
\hline
\end{tabular}

* Subsequently categorised as $<4$ years and $4+$ years.

† 1 US $\$=1 \mathrm{R} \$$ (Real) in 1997.

$\ddagger$ Subsequently categorised as 4 th +3 rd +2 nd quartiles and 1 st quartile.

$\S$ Subsequently categorised as ' $1-2$ ' and ' $3+$ '.

Children whose mothers had been through the same problems but had received precarious or partial aid, and those whose mothers received no help whatsoever (had remained without these services for long periods) presented an increasing risk of being malnourished (odds ratios 1.5 and 2.5 respectively; $P=0.05$; see Table 2).

Table 5 presents results related to the interactions studied (the analysis of the interaction between family income, social support, and malnutrition). The effects of low per capita income and absence of a partner on malnutrition risk were evident, but there was no interaction between variables. On the other hand, a clear interaction was observed between family income and received support score. The inadequacy of financial support during situations adverse to childcare accounted for a 10 -fold increase in malnutrition odds among low-income children (1st quartile), whereas the same scenario had no effect on malnutrition risk among higher-income children (2nd, 3rd and 4th quartiles). These results showed little alteration when adjusted for number of children.

\section{Discussion}

A few limitations of the present study deserve commentary before discussing its results. Despite the careful literature review conducted, no instruments for measuring the various dimensions of social support, validated for use in epidemiological studies on infant health, could be identified. The variables studied were chosen based on the questionnaire presented by Norbeck et al. (1983), developed for evaluating social support in its multiple dimensions among the US population.

Also, the study had low statistical power for identifying smallmagnitude or low-frequency risk factors, so that subtler effects may have been missed. More comprehensive results would require a study based on a larger sample in areas with higher prevalence of malnutrition, so as to minimise the presence of false positives. However, since the bias generated by the inevitable presence of false positives among the cases studied would lead to an effect contrary to the hypothesis under investigation, we believe that the results obtained remain valid. We recommend, for future studies, the use of a more specific criterion for diagnosing malnutrition.

Social support availability may have a diffuse - and difficult to measure - positive effect on child nutritional status by increasing maternal ability to provide adequate care. It may also have a more evident effect by providing aid in situations strongly adverse to infant health and nutrition. The present study attempted to detect both effects by means of variables that measured the existence of a support network; the degree to which mothers believed they could receive help in adverse situations; and the actual support received in face of crises happening after the child was born.

The results indicated that social isolation is a rare phenomenon in the studied population, among both malnourished and normal children, and does not constitute a risk factor for malnutrition. Contrary to what was expected, the absence of individuals friends or relatives - with whom the mother kept frequent contact was not related to the child's nutritional status.

The only variable related to the presumed availability of support (support variable) independently related to malnutrition was the absence of a partner living with the mother. This effect was significant among children of all levels of per capita family income. The population attributable risk percentage for the absence of a partner was 13.3 considering the adjusted odds for schooling, income, and number of children (2.4) and the frequency of mothers without partner among controls $(11 \%)$.

It should be noted that in $98 \%$ of cases and controls the mother's partner was the child's father, which allows us to consider paternal absence as a risk factor for malnutrition during the second year of life. The explanation for such a situation is beyond the reach of the present study, but a few hypotheses may be raised. With the progressive extinction of the extended family, the father may be considered the mother's main supplier of emotional and material support in caring for the child. The most likely hypothesis for explaining the association between 


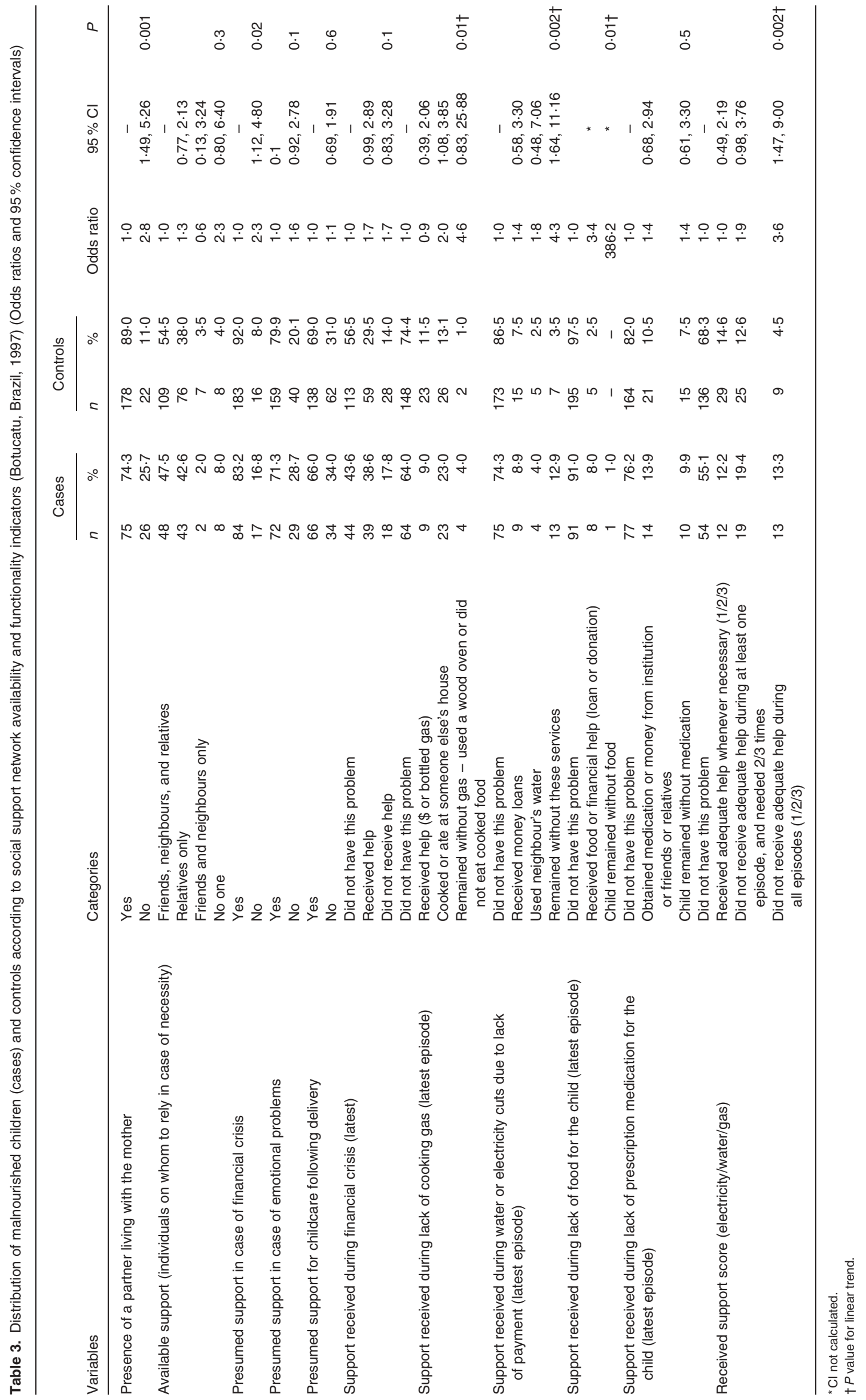


Table 4. Association between variables related to social support and malnutrition: adjusted analyses (Botucatu, Brazil, 1997) (Odds ratios and 95\% confidence intervals)

\begin{tabular}{|c|c|c|c|}
\hline Variable and category & Odds ratio* & $95 \% \mathrm{Cl}$ & $P$ \\
\hline \multicolumn{4}{|l|}{ Presence of partner } \\
\hline Yes & $1 \cdot 0$ & - & \\
\hline No & $2 \cdot 4$ & $1 \cdot 19,4.89$ & 0.015 \\
\hline \multicolumn{4}{|l|}{ Presumed support in case of financial crisis } \\
\hline Yes & $1 \cdot 0$ & - & \\
\hline No & 1.6 & $0.71,3.6$ & 0.25 \\
\hline \multicolumn{4}{|l|}{ Received support score (electricity/water/gas) } \\
\hline Did not have any of the three problems and received adequate help whenever necessary $(1 / 2 / 3$ times) & 1.0 & - & \\
\hline Did not receive adequate help during at least one episode, and needed $2 / 3$ times & 1.3 & $0.62,2.89$ & \\
\hline Did not receive adequate help during all episodes $(1 / 2 / 3)$ & $2 \cdot 4$ & $0.92,6.40$ & $0.180 .06 \dagger$ \\
\hline
\end{tabular}

*Adjusted for mother's schooling ( $<4$ years and $4+$ years), per capita family income ( 4 th +3 rd +2 nd quartiles and 1 st quartile) and number of children $(1-2$ and $3+)$.

$\dagger P$ value for linear trend.

an absent father and malnutrition involves a certain amount of negative economical impact not captured by the inclusion of per capita family income in the model. One possibility would be the dependence of mother and child on individuals with different priorities than those at play within nuclear families, consisting of a couple and their children. To be sure, $90 \%$ of mothers without a partner - cases and controls alike - lived in arrangements including one or both the child's maternal grandparents and other relatives, usually uncles, aunts, and cousins. The division of family income so as to guarantee maximum wellbeing for all family members was questioned even within nuclear families (Desai, 1992). In extended families, in which several generations coexist, it seems reasonable, therefore, to assume that an income allocation pattern exists, which is unfavourable to the child.

The greater involvement of partnerless mothers in professional activities away from home, as well as an eventual decline in the quality of childcare, might also account for the association detected. However, data on maternal employment (not presented in the present article) do not endorse this hypothesis. The absence of a partner living with the mother accounted for only a slight increase in mothers' connection to work outside the household. In addition, there was no association between maternal employment situation and child malnutrition.

There is still the possibility of a relationship between the effect of an absent father and a precarious emotional state on the part of the mother. In a previous study of maternal factors and malnu- trition, carried out using the same population studied here, the presence in the mother of three to four symptoms of depression constituted a significant risk factor for malnutrition (Carvalhaes \& Benício, 2002). The inclusion of the variable 'maternal depression' in the multiple analyses (data not presented), however, had no significant effect on the association between the absence of a partner and malnutrition during the second year of life, which suggests that this is not the main mechanism through which an absent father negatively affects child nutritional status. Another study, also carried out in our environment, indicated an association between the absence of a partner and malnutrition, even after adjustment for per capita income (Olinto et al. 1993).

The most significant result of the present study was the detection of lack of economic support as an important risk factor for malnutrition during the second year of life. Actually, a dose-response gradient was observed, i.e. receiving support, even at precarious levels, determined a risk of malnutrition smaller than that associated with the complete lack of support during economically adverse situations. In fact, the detection of the effect of the lack of material support on nutritional status was striking among low-income children. And, in contrast, the finding that the lack of material support in face of adverse events did not have any effect whatsoever on the risk of malnutrition among the children of higher-income families (and inexistent among the remainder), as revealed by the use of a combination variable for income and received support score. It is plausible to assume that, for the low-income population, help during moments

Table 5. Analysis of the interaction between per capita family income, social support variables, and malnutrition (Botucatu, Brazil, 1997) (Odds ratios and 95\% confidence intervals)

\begin{tabular}{|c|c|c|c|}
\hline Variables and categories & Odds ratio & $95 \% \mathrm{Cl}$ & $P$ \\
\hline Income category and presence of partner ${ }^{*}$ & & & $<0.001$ \\
\hline Higher income† with partner & $1 \cdot 0$ & - & - \\
\hline Higher income† without partner & 3.5 & $1.42,8.76$ & 0.006 \\
\hline Low income $\ddagger$ with partner & 3.6 & $1.79,7.39$ & $<0.001$ \\
\hline Low incomeł without partner & $5 \cdot 1$ & $2.06,12.57$ & 0.001 \\
\hline Income level and received support score* & & & $<0.001$ \\
\hline Higher income $†$ with adequate help or without problems & $1 \cdot 0$ & - & - \\
\hline Higher income $†$ without adequate help & 0.92 & $0.40,2.14$ & 0.85 \\
\hline Low income $\neq$ with adequate help or without problems & $1 \cdot 78$ & $0.85,3.71$ & 0.13 \\
\hline Low income $\neq$ without adequate help & $10 \cdot 1$ & $3.48,29 \cdot 13$ & $<0.001$ \\
\hline
\end{tabular}


of crisis may constitute the difference between eating or not, or between caring or not for the child's health, whereas higherincome mothers can probably continue to fulfil the child's needs by other means.

The population attributable risk percentage for the lack of support in low income families was estimated at $19.1 \%$, considering the odds (10.1) and the prevalence of lack of support amont low income controls $(2.6 \%)$-a value more than twice that attributable to low income with adequate support.

No other study was found in the indexed literature that investigates the relationship between social support and infant malnutrition in developing countries. A single study, employing qualitative methodology, investigated the social support system and its relation to mortality among low-income children without previous severe disease (Bronfman, 1993). In a comparison of social support network structure and functionality between Mexican families with and without multiple child deaths, living in the same area and with the similar socio-economic conditions, the author detected that the former lived without receiving any degree of solidary help. Many families did not even consider such a hypothesis. On the other hand, families without infant deaths had been able to build more structured and efficacious support networks.

It can be concluded that the present results support the hypothesis that the lack of social support has an adverse effect on child nutritional status, and that this effect is more significant among low-income children. Nevertheless, in face of the limitations of the present study, we recommend further studies, preferably with greater samples, and in more populous municipalities. The present results justify more costly studies, with more toilsome methodologies and logistics - namely longitudinal and/or intervention studies - capable of providing information on the chronology of events. We must also mention the need for improved measuring instruments for social support, to be used in epidemiological studies investigating small-child health and nutrition in developing countries.

\section{Acknowledgements}

The present study was developed at the Núcleo de Pesquisas Epidemiológicas em Nutrição e Saúde (NUPENS) of the Universidade de São Paulo and financed by the Brazilian Ministry of Health's 'Nutritional Epidemiology Research Program'. It was part of the $\mathrm{PhD}$ Thesis 'Desnutrição e cuidado infantil: um estudo de casos e controles', presented at the post-graduate course in 'Applied Human Nutrition' at the Faculdade de Ciências Farmacêuticas, Faculdade de Economia e Faculdade de Saúde Pública, Universidade de São Paulo.

\section{References}

Algel R \& Wobey JL (1998) Single motherhood and children's health. J Health Social Behav 34, 198-204.
Barrera M Jr (1986) Distinctions between social support: concepts, measures, and models. Am J Community Psychol 14, 117-128.

Benício MHD’A \& Monteiro CA (1997) Desnutrição Infantil nos Municípios Brasileiros: Risco de Ocorrência (Infant Malnutrition in the Brazilian Municipalities: Risk of Occurrence). Brasília, Brazil: NUPENS/ USP/UNICEF.

Bronfman MN (1993) Multimortalidad y Estructura Familiar: Um Estudo Cualitativo de Las Muertes Infantiles en las Familias (Multimortality and Family Structure: a Qualitative Study of Infant Mortality in Families). Rio de Janeiro: Escola Nacional de Saúde Pública.

Carvalhaes MABL \& Benício MHD'A (2002) Capacidade materna de cuidar e desnutrição infantile (Mother's childcare ability and child malnutrition). Rev Saúde Pública 36, 188-197.

Castro R, Campero L \& Hernández B (1997) La investigación sobre apoyo social en salud: situación atual y nuevos desafios (Investigation on social support in health: prior situation and new challenges). Rev Saúde Pública 31, 198-204.

Cousens SN, Mertens TE, Kirkwood BR, Smith PG \& Feachen RGA (1995) Case Control Studies of Common Childhood Diseases: The Example of Diarrhoea. London: WHO/MacMillan.

Dejin-Karlsson E, Hanson BS, Östergren A, Sjoberg NO \& Marsal K (2000) Association of a lack of psychosocial resources and the risk of giving birth to small for gestational age infants: a stress hypothesis. BJOG 107, 89-100.

Desai S (1992) Children at risk: the role of family structure in Latin America and West Africa. Popul Dev Rev 18, 689-717.

Dixon SD, Levine RA \& Brazelton TB (1982) Malnutrition: a closer look at the problem in a East African Village. Dev Med Child Neurol 24, 670-685.

Engle PL \& Ricciuti HN (1995) Psychosocial aspects of care and nutrition. Food Nutr Bull 16, 356-377.

Hosmer DM \& Lemeshow S (1989) Applied Logistic Regression. New York: John Wiley and Sons.

Kerr MAD, Bogues JL \& Kerr DS (1978) Psychosocial functioning of mothers of malnourished children. Pediatrics 62, 778-784.

Morley D, Bicknell J \& Woodland M (1968) Factors influencing the growth and nutritional status of infants and young children in a Nigerian Village. Trans R Soc Trop Med Hyg 62, 164-199.

Mulroy EA (1997) Building a neighborhood network: interorganizational collaboration to prevent child abuse and neglect. Soc Work 42, $255-264$

Norbeck JS, Lindsey AM \& Carrieri V (1983) Further development of the Norbeck social support questionnaire: normative data and validity testing. Nurs Res 32, 4-9.

Olinto MTA, Victora CG, Barros FC \& Tomasi E (1993) Determinantes da desnutrição infantil em uma população de baixa renda: um modelo de análise hierarquizada (Determinants of infant malnutrition in a low income population: a model of hierarchical analysis). Cad Saúde Pública 9, Suppl., 14-27.

Tarkka MT, Paunomen M \& Laipalla P (1999) Social support provided by public nurses and coping of first-time mothers with child care. Public Health Nurs 16, 114-119.

World Health Organization (1995) Physical Status: The Use and Interpretation of Anthropometry, WHO-Technical Report Series, 854. Geneva: WHO. 